\title{
NUMERICAL INVESTIGATION OF NATURAL CONVECTION HEAT TRANSFERFROM SQUARE CYLINDER IN AN ENCLOSED ENCLOSURE FILLED WITH NANOFLUIDS
}

\author{
Omar M. Ali ${ }^{1}$ and Ghalib Y. Kahwaji ${ }^{2}$ \\ ${ }^{1}$ Department of Mech. Eng., University of Zakho, Iraq \\ omarsulivany@gmail.com. \\ ${ }^{2}$ Department of Mech. Eng., Rochester Institute of Technology-Dubai, UAE \\ gykcad@rit.edu
}

\begin{abstract}
The enhancement of natural convection heat transfer using nanofluids from horizontal square cylinder placed in a square enclosure is investigated numerically. Water-based $\mathrm{Cu}$ is used as the working nanofluid. The investigation covered a range of Rayleigh numbers of $10^{4}-10^{6}$, nanoparticles volume fraction of $(0<\varphi \leq 0.2)$, enclosure width to cylinder height ratio, W/H of 2.5. The investigation includes the solution of the governing equations in the Vorticity-Stream function space with the aid of a body fitted coordinate system. Algebraic grid generation is used in the initial transformations, followed by an elliptic transformation to complete the grid generation to computational domain. The resulting discretized system of equations is solved using an ADI method. The built code is validated and the results showed an increase in average Nusselt number with increasing the volume fraction of the nanoparticles for the whole range of Rayleigh number. The isotherms are nearly similar when the volume fraction of nanoparticles is increased from 0 to 0.2 for each Rayleigh number but a change in the streamlines is observed.
\end{abstract}

\section{KEYWORDS:}

Heat Transfer, Square Cylinder, Square Enclosure, Numerical.

\section{NOMENCLATURE}

\begin{tabular}{|c|c|c|c|c|c|}
\hline Symbol & $\underline{\text { Definition }}$ & $\underline{\text { Unit }}$ & $\frac{\text { Symb }}{\underline{\text { ol }}}$ & $\underline{\text { Definition }}$ & $\underline{\text { Unit }}$ \\
\hline$d_{i, j}$ & $\begin{array}{l}\text { Source term in equation, } \\
\text { eqn. (18). }\end{array}$ & & \multicolumn{3}{|c|}{ Greek Symbols } \\
\hline $\mathrm{f}$ & $\begin{array}{l}\text { Volume fraction of } \\
\text { nanofluid. }\end{array}$ & & $\Delta \mathrm{T}$ & Temperature difference. & ${ }^{\circ} \mathrm{C}$ \\
\hline $\mathrm{h}$ & $\begin{array}{l}\text { Convective heat transfer } \\
\text { coefficient. }\end{array}$ & $\begin{array}{l}\mathrm{W} / \mathrm{m}^{2} \\
{ }^{\circ} \mathrm{C}\end{array}$ & $\mu$ & Viscosity of the air. & $\mathrm{kg} / \mathrm{ms}$ \\
\hline $\mathrm{H}$ & Height of the cylinder. & $\mathrm{m}$ & $\beta$ & $\begin{array}{l}\text { Coefficient of thermal } \\
\text { expansion. }\end{array}$ & $1 /{ }^{\circ} \mathrm{C}$ \\
\hline $\mathrm{J}$ & Jacobian. & & $\eta$ & $\begin{array}{l}\text { Vertical axis in computational } \\
\text { domain. }\end{array}$ & \\
\hline $\mathrm{k}$ & $\begin{array}{l}\text { Thermal conductivity- } \\
\text { air. }\end{array}$ & $\begin{array}{c}\mathrm{W} / \mathrm{m} .^{\circ} \\
\mathrm{C}\end{array}$ & $\xi$ & $\begin{array}{l}\text { Horizontal axis in } \\
\text { computational domain. }\end{array}$ & \\
\hline $\mathrm{Nu}$ & Average Nusselt number & & $\Psi$ & Dimensionless stream function. & \\
\hline
\end{tabular}




\begin{tabular}{|c|c|c|c|c|c|}
\hline $\mathrm{p}$ & Pressure. & $\mathrm{N} / \mathrm{m}^{2}$ & $\omega$ & Vorticity. & $1 / \mathrm{s}$ \\
\hline $\mathrm{P}$ & $\begin{array}{l}\text { Coordinate control } \\
\text { function. }\end{array}$ & & $\varpi$ & Dimensionless vorticity. & \\
\hline $\operatorname{Pr}$ & Prandtl number, $(v / \alpha)$. & & $v$ & Kinematic viscosity. & $\mathrm{m}^{2} / \mathrm{s}$ \\
\hline Q & $\begin{array}{l}\text { Coordinate control } \\
\text { function. }\end{array}$ & & $\theta$ & Dimensionless temperature. & \\
\hline $\mathrm{R}$ & $\begin{array}{l}\text { Maximum absolute } \\
\text { residual }\end{array}$ & & $\varphi$ & Volume fraction of nanofluid. & \\
\hline $\mathrm{Ra}$ & $\begin{array}{l}\text { Raylieh number, } \\
\left(\mathrm{g} \beta \Delta \mathrm{TH}^{3} / v \alpha\right) \text {. }\end{array}$ & & $\phi$ & Dependent variable. & \\
\hline $\mathrm{t}$ & Time. & $\begin{array}{c}\text { second } \\
\text { s }\end{array}$ & $\psi$ & Stream Function. & $1 / \mathrm{sec}$ \\
\hline $\mathrm{T}$ & Temperature. & ${ }^{\circ} \mathrm{C}$ & \multicolumn{2}{|c|}{ Subscript } & \\
\hline $\mathrm{u}$ & Velocity in $\mathrm{x}$-direction. & $\mathrm{m} / \mathrm{s}$ & $\mathrm{s}$ & Cylinder surface. & \\
\hline $\mathrm{v}$ & Velocity in y-direction. & $\mathrm{m} / \mathrm{s}$ & $\infty$ & Environment. & \\
\hline $\mathrm{W}$ & Enclosure Width. & $\mathrm{cm}$ & $\mathrm{X}$ & Derivative in $\mathrm{x}$-direction. & \\
\hline$W$ & Relaxation factor. & & $\mathrm{Y}$ & Derivative in $y$-direction. & \\
\hline $\mathrm{x}$ & $\begin{array}{l}\text { Horizontal direction in } \\
\text { physical domain. } \\
\text { Dimensionless }\end{array}$ & $\mathrm{m}$ & $\xi$ & Derivative in $\xi$-direction. & \\
\hline $\mathrm{X}$ & $\begin{array}{l}\text { horizontal direction in } \\
\text { physical domain. }\end{array}$ & & $\mathrm{D}$ & Circular cylinder diameter. & \\
\hline $\mathrm{y}$ & $\begin{array}{l}\text { Vertical axis in physical } \\
\text { domain. }\end{array}$ & $\mathrm{m}$ & $\psi$ & Stream function. & \\
\hline $\mathrm{Y}$ & $\begin{array}{l}\text { Dimensionless vertical } \\
\text { axis in physical domain. }\end{array}$ & & $\mathrm{T}$ & Temperature. & \\
\hline
\end{tabular}

\section{INTRODUCTION}

There are a number of practical applications of natural convection heat transfer from very long horizontal cylinders of noncircular sections. This subject has received only limited attention in the literature, Ali, [1]. Nanofluids are defined as fluids which consist of a base fluid such as water with nano-size particles (e.g. metal, metal oxide, and carbon materials), suspended in it. The size of the nanoparticles is between 1-100 $\mathrm{nm}$. The dispersion of highly-conductive nanoparticles into the base liquids is seen as a promising approach to improve the performance of the engineered heat transfer fluids, Choi [2]. Zi-Tao Yu, et al. [3], reviewed the reported literature bout laminar natural convection of nanofluids in confined regions (square and rectangular cavities, horizontal annuli and triangular enclosures), for a variety of combinations of base liquids and nanoparticles. Nanofluids were considered as single phase fluids and the presence of nanoparticles plays a role in modifying the macroscopic thermo-physical properties of their base liquids. A large number of studies have dealt with the mechanism s of thermo-physical properties of the nanofluids, Zi-Tao $\mathrm{Yu}$, et al, [4]. The results indicated a gradual decrease in Nusselt number with the decrease of the volume at constant Rayleigh number.

Natural convection heat transfer in horizontal annuli using variable properties of $\mathrm{Al}_{2} \mathrm{O}_{3}$-water nanofluid is studied numerically by Eiyad Abu-Nada [5], where the heat transfer enhancement in the annulus is evaluated using different models of viscosity and thermal conductivity. It was observed that the Nguyen et al. data and Brinkman model gives completely different predictions at $\mathrm{Ra} \geq 10^{4}$ where the difference in prediction of Nusselt number reached $30 \%$.

Hakan, et al, [6], studied the heat transfer and fluid flow due to buoyancy forces in a partially heated enclosure using different types of nanoparticles. A heater is located to the left vertical wall with a finite length. The governing equations were solved using finite volume technique. 
Different types of nanofluids are used with variable range of Rayleigh number, height of heater, location of heater, aspect ratio and volume fraction of nanoparticles. Nusselt number increased with the volume fraction of nanoparticles for the whole range of Rayleigh number. Heat transfer also enhances with increasing of height of heater. It was found that the heater location affects the flow and temperature fields and the heat transfer enhancement, using nanofluids, is more pronounced at low aspect ratio than at high aspect ratio.

The present work deals with numerical investigation of natural convection heat transfer fora water-based $\mathrm{Cu}$ nanofluid and a square horizontal cylinder situated in closed square cavity. The work investigates the effect of nanofluids on the flow and heat transfer characteristics. The study uses different Rayleigh numbers, and different volume fraction of nanoparticles.

\section{MATHEMATICAL FORMULATION}

Figure (1) displays a schematic diagram of the flow between the heated horizontal square cylinder and the enclosure. The fluid is water containing nano-sized particles of copper. It is assumed that the fluid is incompressible, the base fluid (water) and nanoparticles are in thermal equilibrium and no slip condition occurs between them. The governing equations were solved under the assumptions that the flow is laminar, no internal heat sources, flow is two-dimensional and Boussinesq approximation applies. The thermo-physical properties, given in table (1), are assumed to be constant, [6].

Table 1. Thermo-physical properties of the pure fluid and the nanoparticles, Hakan, et al, [6]

\begin{tabular}{|c|c|c|}
\hline Physical Properties & Fluid phase (water) & Nanoparticles $(\mathrm{Cu})$ \\
\hline $\mathrm{C}_{\mathrm{p}}\left(\mathrm{J} / \mathrm{kg} \cdot{ }^{\circ} \mathrm{K}\right)$ & 4197 & 385 \\
\hline$\rho\left(\mathrm{kg} / \mathrm{m}^{3}\right)$ & 997.1 & 8933 \\
\hline $\mathrm{k}\left(\mathrm{W} / \mathrm{m}^{\circ}{ }^{\circ} \mathrm{K}\right)$ & 0.613 & 1163.1 \\
\hline$\alpha \times 10^{7}\left(\mathrm{~m}^{2} / \mathrm{sec}\right)$ & 1.47 & 1.67 \\
\hline$\beta \times 10^{-5}\left(\mathrm{~m}^{2} / \mathrm{sec}\right)$ & 21 & \multirow{2}{*}{} \\
\hline
\end{tabular}

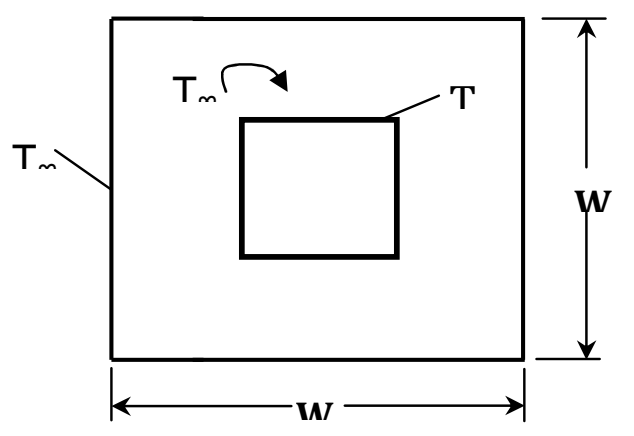

Figure 1. Configuration of cylinder-enclosure combination

The steady, incompressible continuity equation is given by, [6]:

$$
\frac{\partial u}{\partial x}+\frac{\partial v}{\partial y}=0
$$

The $\mathrm{x}$-momentum equation is: 


$$
\begin{aligned}
& \frac{\partial u}{\partial t}+u \frac{\partial u}{\partial x}+v \frac{\partial u}{\partial y}=-\frac{1}{\rho_{n f}} \frac{\partial p}{\partial x}+v_{n f}\left(\frac{\partial^{2} u}{\partial x^{2}}+\frac{\partial^{2} u}{\partial y^{2}}\right) \\
& +g \frac{(\rho \dot{\beta})_{n f}}{\rho_{n f}} g \Delta T
\end{aligned}
$$

The $y$-momentum equation is:

$$
\begin{aligned}
& \frac{\partial v}{\partial t}+u \frac{\partial v}{\partial x}+v \frac{\partial v}{\partial y}=-\frac{1}{\rho_{n f}} \frac{\partial p}{\partial x}+v_{n f}\left(\frac{\partial^{2} v}{\partial x^{2}}+\frac{\partial^{2} v}{\partial y^{2}}\right) \\
& +g \frac{(\rho \dot{\beta})_{n f}}{\rho_{n f}} g \Delta T
\end{aligned}
$$

And the energy equation is given by:

$$
\frac{\partial T}{\partial t}+u \frac{\partial T}{\partial x}+v \frac{\partial T}{\partial y}=\alpha_{n f}\left(\frac{\partial^{2} T}{\partial x^{2}}+\frac{\partial^{2} T}{\partial y^{2}}\right)
$$

With Boussinesq approximations, the density is constant for all terms in the governing equations except for the buoyancy force term where the density is a assumed a linear function of the temperature.

$$
\rho=\rho_{o}(1-\dot{\beta} \Delta T)
$$

where $\beta$ is the coefficient of thermal expansion. The stream function $(\psi)$ and vorticity $(\omega)$ are defined as follows, Anderson [7], and Petrovic [8]:

$$
\begin{aligned}
& u=\frac{\partial \psi}{\partial y}, \quad v=-\frac{\partial \psi}{\partial x} \\
& \omega=\frac{\partial v}{\partial x}-\frac{\partial u}{\partial y}
\end{aligned}
$$

Or $\omega=\nabla \times \vec{V}$

Substitution in the governing equations yields:

Energy Equation:

$$
\frac{\partial \theta}{\partial t}+\frac{\partial \Psi}{\partial y} \frac{\partial \theta}{\partial x}-\frac{\partial \Psi}{\partial x} \frac{\partial \theta}{\partial y}=\frac{\partial}{\partial x}\left(\lambda \frac{\partial \theta}{\partial x}\right)+\frac{\partial}{\partial y}\left(\lambda \frac{\partial \theta}{\partial y}\right)
$$

Momentum Equation: 
International Journal of Recent advances in Mechanical Engineering (IJMECH) Vol.4, No.4, November 2015

$$
\begin{aligned}
& \frac{\partial \varpi}{\partial t}+\frac{\partial \Psi}{\partial y} \frac{\partial \varpi}{\partial x}-\frac{\partial \Psi}{\partial x} \frac{\partial \varpi}{\partial y}=\left[\frac{\operatorname{Pr}}{(1-\varphi)^{0.25}\left((1-\varphi)+\varphi \frac{\rho_{s}}{\rho_{f}}\right)}\right] \\
& \left(\frac{\partial^{2} \bar{\partial}}{\partial x^{2}}+\frac{\partial^{2} \Phi}{\partial y^{2}}\right)+\operatorname{Ra} \operatorname{Pr}\left[\frac{\frac{1}{\frac{(1-\varphi) \frac{\rho_{f}}{\rho_{s}}+1}{\beta_{f}}+}}{\frac{1}{\frac{\varphi}{(1-\varphi)} \frac{\rho_{f}}{\rho_{s}}+1}}\right] \frac{\partial \theta}{\partial x}
\end{aligned}
$$

Continuity Equation:

$\frac{\partial^{2} \Psi}{\partial x^{2}}+\frac{\partial^{2} \Psi}{\partial y^{2}}=-\varpi$

Where

$\lambda=\frac{\frac{k_{n f}}{k_{f}}}{(1-\varphi)+\varphi \frac{\left(\rho C_{P}\right)_{s}}{\left(\rho C_{P}\right)_{f}}}$

$\alpha_{n f}=\frac{k_{e f f}}{\left(\rho C_{P}\right)_{n f}}$

The effective density and heat capacitance of the nanofluid are calculated from:

$\rho_{n f}=(1-\varphi) \rho_{f}+\varphi \rho_{s}$

$\left(\rho C_{P}\right)_{n f}=(1-\varphi)\left(\rho C_{P}\right)_{f}+\varphi\left(\rho C_{P}\right)_{S}$

Assuming that the nanoparticles are spherical, the effective thermal conductivity of the nanofluid is approximated by the Maxwell-Garnetts model:

$\frac{k_{n f}}{k_{f}}=\frac{k_{s}+2 k_{f}-2 \varphi\left(k_{f}-k_{s}\right)}{k_{S}+2 k_{f}+\varphi\left(k_{f}-k_{S}\right)}$

The viscosity of the nanofluid can be considered as that of a base fluid containing dilute suspension of fine spherical particles, Brinkman [9]:

$\mu_{n f}=\frac{\mu_{f}}{(1-\varphi)^{2.5}}$

Introducing the following dimensionless variables: 
$X=\frac{x}{H}, Y=\frac{y}{H} \quad, \quad U=\frac{u H}{\alpha_{f}}, \quad V=\frac{v H}{\alpha_{f}}$,

$\tau=\frac{t \alpha_{f}}{H^{2}}, \Psi=\frac{\psi}{\alpha_{f}}, \quad \varpi=\frac{\omega H^{2}}{\alpha_{f}}, \quad \theta=\frac{\mathrm{T}-\mathrm{T}_{\infty}}{\mathrm{T}_{c}-\mathrm{T}_{\infty}}$

Transforms the governing equations to:

$a_{\phi}\left\{\frac{\partial \phi}{\partial t}+\frac{1}{J}\left[\left(\frac{\partial \psi}{\partial \eta} \phi\right)_{\xi}-\left(\frac{\partial \psi}{\partial \xi} \phi\right)_{\eta}\right]\right\}=\nabla\left(b_{\phi} \nabla \phi\right)+d_{\phi}$

Where $\phi$ is any dependent variable. The governing equations are obtained by replacing the dependent variable $\phi i n$ the three governing equations as follow:

\begin{tabular}{|c|c|c|c|}
\hline$\phi$ & $\mathrm{a}_{\phi}$ & $\mathrm{b}_{\phi}$ & $\mathrm{d}_{\phi}$ \\
\hline$\psi$ & 0 & 1 & $\omega$ \\
\hline$\omega$ & 1 & $\frac{\operatorname{Pr}}{\left.(1-\varphi)^{022}(1-\varphi)+\varphi \frac{\rho_{s}}{\rho_{f}}\right)}$ & $\operatorname{Ra} \operatorname{Pr}\left[\frac{1}{\frac{(1-\varphi)}{\varphi} \frac{\rho_{f}}{\rho_{s}}+1} \frac{\beta_{s}}{\beta_{f}}+\frac{1}{\frac{\varphi}{(1-\varphi)} \frac{\rho_{f}}{\rho_{s}}+1}\right]\left[\left(y_{\eta} \theta\right)_{\xi}-\left(y_{\xi} \theta\right)_{\eta}\right]$ \\
\hline $\mathrm{T}$ & 1 & $\lambda$ & 0 \\
\hline
\end{tabular}

Note that $\frac{\partial \phi}{\partial t}$ represents the unsteady term, $\frac{1}{J}\left[\left(\frac{\partial \psi}{\partial \eta} \phi\right)_{\xi}-\left(\frac{\partial \psi}{\partial \xi} \phi\right)_{\eta}\right]$ is the convective term,

$\nabla\left(b_{\phi} \nabla \phi\right)$;is the diffusion term, and $d_{\phi}$ is the source term.

\subsection{Grid Generation}

The initial computational grid, generated using an algebraic grid generation technique are fed into elliptic, Poisson equations to generate the final orthogonal computational grid points:

$\xi_{x x}+\xi_{y y}=P(\xi, \eta)$

$\eta_{x x}+\eta_{y y}=Q(\xi, \eta)$

Interchanging dependent and independent variables for equations (19a, and b), gives:

$\alpha x_{\xi \xi}-2 \beta x_{\xi \eta}+\gamma x_{\eta \eta}+$
$J^{2}\left(P x_{\xi}+Q x_{\eta}\right)=0$ 


$$
\begin{aligned}
& \alpha y_{\xi \xi}-2 \beta y_{\xi \eta}+\gamma y_{\eta \eta}+ \\
& J^{2}\left(P y_{\xi}+Q y_{\eta}\right)=0
\end{aligned}
$$

Where $\alpha=x_{\eta}^{2}+y_{\eta}^{2} \quad, \beta=x_{\xi} x_{\eta}+y_{\xi} y_{\eta}$, and $\quad \gamma=x_{\xi}^{2}+y_{\xi}^{2}$

The coordinate control functions $\mathrm{P}$ and $\mathrm{Q}$ are chosen to influence the structure of the grid, [10]. The solution of these equations is obtained using Successive over Relaxation (SOR) method with relaxation factor value equal to 1.4, [11and 12].The transformed computational grid is shown in figure (2) below.

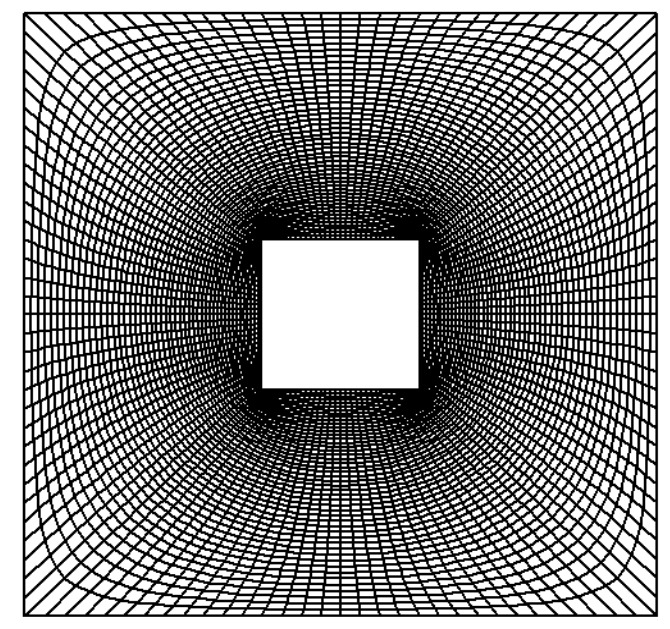

Figure 2. Physical to computational domains transformation using elliptic grid generation.

\subsection{Solution Procedure}

The governing equations were converted into algebraic equations using Finite Volume based Finite Difference method, Ferziger [13].

The hybrid scheme (of the central and the upwind differencing schemes) is used to avoid the instability of the central differencing scheme (second order for convective term) at high Peclet number (Cell Reynolds Number) and the inaccuracy of the upwind differencing scheme (first order for convective term).

$$
\begin{aligned}
& a_{P} \phi_{P}=a_{E} \phi_{E}+a_{W} \phi_{W}+a_{N} \phi_{N}+a_{S} \phi_{S}+a_{P}^{o} \phi_{P}^{o}+ \\
& a_{M}\left(\phi_{i+1, j+1}-\phi_{i-1, j-1}-\phi_{i+1, j-1}+\phi_{i-1, j+1}\right)+d_{i, j} \\
& a_{P}=a_{E}+a_{W}+a_{N}+a_{S}+a_{P}^{o}
\end{aligned}
$$

The resulting algebraic equation is solved using alternating direction implicit method ADI in two sweeps; in the first sweep, the equations are solved implicitly in $\xi$-direction using Cyclic TriDiagonal Matrix Algorithm (CTDMA), because of its cyclic boundary conditions, and explicitly in $\eta$-direction. In the second sweep, the equations are solved implicitly in $\eta$-direction using TriDiagonal Matrix Algorithm (TDMA) and explicit in $\xi$-direction. 
International Journal of Recent advances in Mechanical Engineering (IJMECH) Vol.4, No.4, November 2015

The solution of the stream function equation was obtained using Successive Over-Relaxation method (SOR).

The initial conditions of the flow between heated cylinder and vented enclosure are:

$\Psi=0, \theta=0, \omega=0 ;$ for $\mathrm{t}=0$

The temperature boundary condition of the cylinder surface was assumed as constant.

$\left.\frac{\partial \theta}{\partial \eta}\right|_{m}=0 ;$ atthe enclosure wall

Using $2^{\text {nd }}$ order difference equation, the temperature at the enclosure surface becomes:

$\theta_{i, m}=\frac{4}{3} \theta_{i, m-1}-\frac{1}{3} \theta_{i, m-2}$

Vorticity boundary conditions, Roache [14], are

$\varpi=\frac{2 \gamma}{J^{2}}\left(\psi_{i, m}-\psi_{i, m-1}\right) \quad$ at enclosure wall

$\varpi=\frac{2 \gamma}{J^{2}}\left(\psi_{i, 1}-\psi_{i, 2}\right) \quad$ at cylinder surface

The stream function of the cylinder and the enclosure are assumed equal to zero.

The Nusselt number $\mathrm{Nu}$ is a non-dimensional heat transfer coefficient that calculated in the following manner:

$N u=\frac{h D}{k_{f}}$

The heat transfer coefficient is expressed as

$\mathrm{h}=\frac{\mathrm{q}_{\mathrm{w}}}{\mathrm{T}_{\mathrm{H}}-\mathrm{T}_{\mathrm{L}}}$

The thermal conductivity is expressed as

$\mathrm{k}_{\mathrm{nf}}=-\frac{\mathrm{q}_{\mathrm{w}}}{\partial \theta / \partial \mathrm{n}}$

Substituting Equations (24), (25), and (7) into Equation (23), using the dimensionless quantities, the Nusselt number on the left wall is written as:

$$
N u=-\frac{k_{n f}}{k_{f}} \int_{0}^{2 \pi} \frac{\partial \theta}{\partial n} \partial \zeta
$$

The derivative of the non-dimensional temperature is calculated using the following formula, Fletcher [15]: 


$$
\left.\frac{\partial \theta}{\partial n}\right|_{\eta=\text { const. }}=\frac{1}{J \sqrt{\gamma}}\left(-\beta \theta_{\xi}+\gamma \theta_{\eta}\right)=\frac{\sqrt{\gamma}}{J} \frac{\partial \theta}{\partial \eta}
$$

And $\theta_{\xi}=0$ at cylinder surface

A computer program in (Fortran 90) was built to execute the numerical algorithm explained above; it is general for a natural convection from heated cylinder situated in an enclosure.

\section{RESULTS AND DISCUSSION}

The developed numerical solution is used to solve the natural convection heat transfer from a square horizontal cylinder placed in a square enclosure. The enclosure is filled with nano-fluid with Prandtl number of 6.2. The enclosure width to cylinder characteristic length ratio $\mathrm{W} / \mathrm{H}=2.5$, Rayleigh numbers of $10^{4}, 10^{5}$, and $10^{6}$, and volume fractions of nanofluid $\varphi$ are $0,0.05,0.1,0.15$ and 0.2 were studied.

The convergence criteria are chosen as $\mathrm{RT}<10^{-6}, \mathrm{R} \psi<10^{-6}$ and $\mathrm{R} \omega<10^{-6}$ for $\mathrm{T}, \psi$ and $\omega$ respectively. When all the three criteria are satisfied, the convergent results are subsequently obtained.

\subsection{Stability and Grid Independency Study}

The stability of the numerical method is investigated for the case $\operatorname{Ra}=10^{5}, \mathrm{~W} / \mathrm{D}=2.5, \operatorname{Pr}=0.7$. Three time steps are chosen with values $1 \times 10^{-4}, 5 \times 10^{-4}, 5 \times 10^{-6}$. The maximum difference between the values of $\mathrm{Nu}$ with different time steps is $2 \%$. The grid-independence of numerical results is studied for the case with $\mathrm{Ra}=10^{4}$, and $10^{5}, \mathrm{~W} / \mathrm{D}=2.5, \mathrm{Pr}=6.2$. Three mesh sizes of $96 \times 25$, $128 \times 45$, and $192 \times 50$ were used for the grid-independence study. It is noted that the total number of grid points for the above three mesh sizes is 2425,5805 , and 9650 respectively. Numerical experiments showed that when the mesh size is above $96 \times 45$, the computed Nu remain the same.

\subsection{Validation Test}

The developed code validation included numerical investigation of the natural convection problem for a low temperature outer square enclosure and high temperature inner circular cylinder. The average Nusselt numbers and maximum stream function $\psi_{\max }$ are compared with the benchmark values by Moukalled and Acharya [16]. Comparisons are conducted for Prandtl number $\operatorname{Pr}=0.7$, enclosure width to cylinder diameter ratios $(\mathrm{W} / \mathrm{H}=2.5)$ and $\mathrm{Ra}=10^{4}$ and $10^{5}$ as given in table (2). The results show a good agreement with Moukalled and Acharya [16]. 
International Journal of Recent advances in Mechanical Engineering (IJMECH) Vol.4, No.4, November 2015

Table (2): Comparisons of Nusselt numbers and maximum stream function

\begin{tabular}{|c|c|c|c|c|c|}
\hline \multirow{3}{*}{ L/D } & \multirow{3}{*}{$\mathrm{Ra}$} & \multicolumn{2}{|c|}{$\psi_{\max }$} & \multicolumn{2}{|c|}{$\overline{N u}$} \\
\cline { 4 - 6 } & & Present & $\begin{array}{c}\text { Moukalled and } \\
\text { Acharya [16] }\end{array}$ & Present & $\begin{array}{c}\text { Moukalled and } \\
\text { Acharya [16] }\end{array}$ \\
\hline 5.0 & \multirow{3}{*}{$10^{4}$} & 2.45 & 2.08 & 1.7427 & 1.71 \\
\cline { 4 - 6 } & 3.182 & 3.24 & 0.9584 & 0.97 \\
\cline { 4 - 6 } & & 5.22 & 5.4 & 0.4274 & 0.49 \\
\hline 1.67 & 10.10 & 10.15 & 3.889 & 3.825 \\
\hline 5.0 & \multirow{3}{*}{$10^{5}$} & 8.176 & 8.38 & 4.93 & 5.08 \\
\cline { 1 - 4 } & & 4.8644 & 5.10 & 6.23 & 6.212 \\
\hline 1.67 & & & & & \\
\hline
\end{tabular}

\subsection{Flow Patterns and Isotherms}

The flow patterns and isotherms displayed in figures (3-5) are for volume fraction range $\varphi=0$ to 0.2 . Figure (3) shows a comparison of streamlines and isotherms between $\mathrm{Cu}$-water nanofluid $(\varphi=0.1)$ and pure fluid $(\varphi=0)$ for $\mathrm{W} / \mathrm{H}=2.5$ with Rayleigh number values $\mathrm{Ra}=10^{4}, 10^{5}$, and $10^{6}$. At $\mathrm{Ra}=10^{4}$ and $10^{5}$, the isotherms of two cases are nearly identical. There are some differences in isotherms between the two cases for $\mathrm{Ra}=10^{6}$. The isotherms at the upper region above the square cylinder for $\varphi=0.1$ are different as compared with pure fluid. The width of the thermal plume for pure fluid is narrower than those for $\varphi=0.1$. The same behavior occurs with thermal plumes at the corners of the square cylinder. The isotherms are symmetrical around vertical center line above the square cylinder for pure fluid, while, the isotherms appear as nearly asymmetrical around vertical center line for $\varphi=0.1$. The aspects of the streamlines are different for two cases. The flow circulation for $\varphi=0.1$ is greater than those for pure fluid for all Rayleigh numbers. Table (3) display the values of maximum stream function for pure fluid and $\varphi=0.1$ with $\mathrm{Ra}=10^{4}, 10^{5}, 10^{6}$.

Table 3. Comparisons of maximum stream functions between pure fluid and $\varphi=0.1$

\begin{tabular}{|c|c|c|}
\hline \multirow{2}{*}{ Ra } & \multicolumn{2}{|c|}{ Maximum Stream Function } \\
\cline { 2 - 3 } & Pure fluid & $\varphi=0.1$ \\
\hline $10^{4}$ & 2.071321 & 4.2414815 \\
\hline $10^{5}$ & 4.7592694 & 6.95287233 \\
\hline $10^{6}$ & 8.893556 & 12.736855 \\
\hline
\end{tabular}

At $\mathrm{Ra}=10^{4}$, the dominant heat transfer is the conduction, therefore, the streamlines of the two cases are nearly similar except that the sizes of the internal eddies are different. At $\mathrm{Ra}=10^{5}$, the streamlines appear as nearly kidney-shaped for two cases. Two circular tiny eddies display at the upper region near the center line above the square cylinder. For $\varphi=0.1$, the flow cover the most region between the square cylinder and the enclosure, therefore; the stagnant area is very small. The coverage of the flow reduces for pure fluid, therefore; the stagnant area increases. The densely package of the flow for $\varphi=0.1$ is more than those for pure fluid. At $\mathrm{Ra}=10^{6}$, the flow moves upward for two cases. The coverage of the flow in the region between the square cylinder 
and the enclosure for pure fluid is more than those for $\varphi=0.1$. The densely packed of the kidneyshaped eddies and tiny eddies for pure fluid are more than those for $\varphi=0.1$.
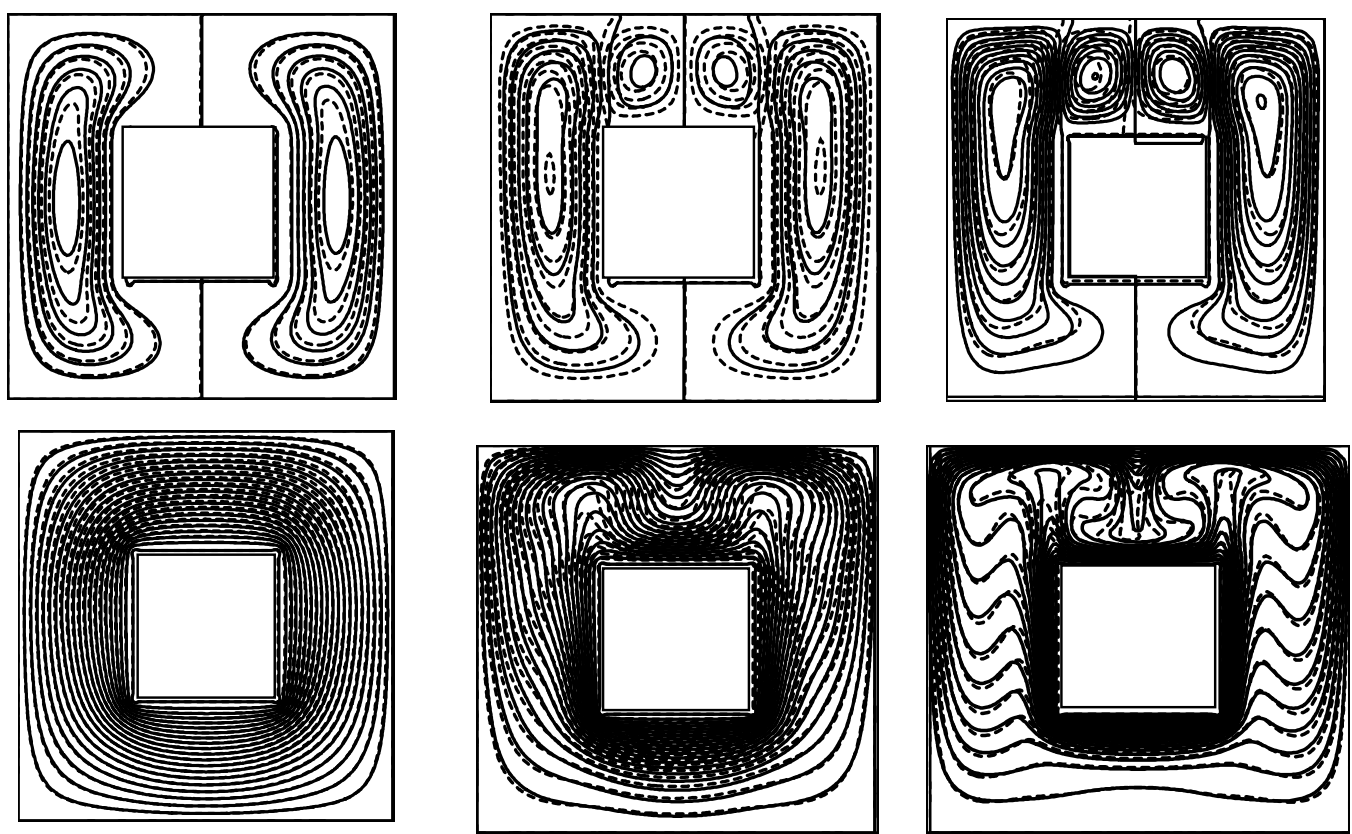

Figure 3. Streamlines (on the top) and Isotherms (on the bottom) for $\mathrm{Cu}$-water nanofluids (- - -), pure

Figures (4-5) display the streamlines and isotherms for $\mathrm{W} / \mathrm{H}=2.5$, and nanofluid volume fractions $\varphi=0.05,0.1,0.15$ and 0.2 . The strength of the flow circulation varies with the variation of the Rayleigh number values. The maximum stream function value varies between $\Psi_{\max }=0.94$ at $\mathrm{Ra}=10^{4}$ and $\varphi=0.05$ to $\Psi_{\max }=43$ at $\mathrm{Ra}=10^{6}$ and $\varphi=0.2$. At $\mathrm{Ra}=10^{4}$, the flow circulation is weak, therefore; the maximum stream function value is small. The flow is symmetrical about the vertical line through center of the square cylinder. The flow patterns appear as a curved kidneyshaped single longitudinal eddy. The eddy core is small and the vertical boundary layers are thick, indicative of the weak driving buoyancy. As the nanofluid volume fraction increases to $\varphi=0.1$, the flow circulation enhances $\left(\Psi_{\max }=1.19\right)$ and the eddy core becomes wider. The flow strength further increases for $\varphi=0.15\left(\Psi_{\max }=1.44\right)$ and $0.2\left(\Psi_{\max }=1.675\right)$, however, the core starts growing smaller indicative of the hydrodynamic boundary layer growth with viscosity. At $\mathrm{Ra}=10^{5}$, the strength of the flow circulation becomes higher and two tiny eddies appear at the upper region of the cylinder near the vertical center line. The tiny eddies appear as rings. The densely packed of the flow for $\phi=0.1$ and 0.15 are more than other flows. As Rayleigh number increases to $\mathrm{Ra}=10^{6}$, the flow becomes stronger and the maximum stream function increases for all cases $\left(\Psi_{\max }=27.4,32.6,37.6\right.$, and 43.0 for $\varphi=0.05,0.1,0.15$ and 0.2 respectively). The flow is asymmetrical about the vertical center line. The streamlines near the bottom enclosure wall move to the upward that lead to an increase in the stagnant area. The kernel eddy size becomes more and it takes a triangular shape. The flow region moves upwards and the lower stagnant area enlarges with increasing the volume fractions of the nanofluids. 
International Journal of Recent advances in Mechanical Engineering (IJMECH) Vol.4, No.4, November 2015
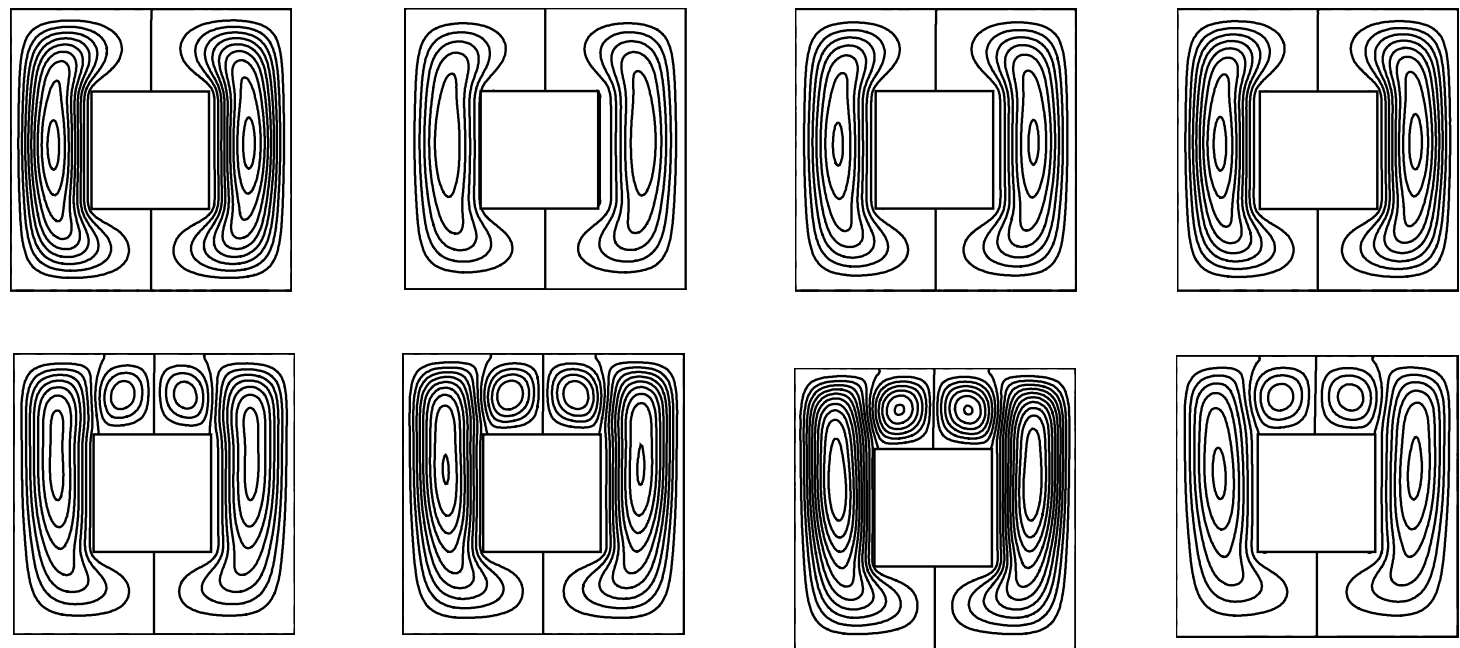

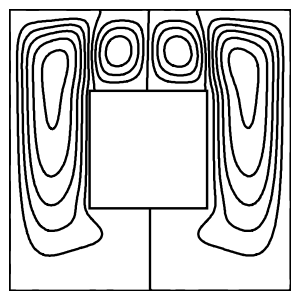

$\varphi=0.05$

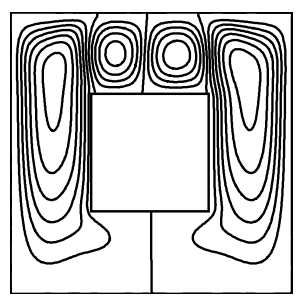

$\varphi=0.1$

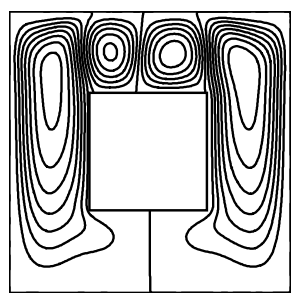

$\varphi=0.15$

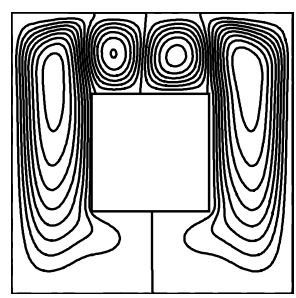

$\varphi=0.2$

Figure 4. Effect of volume fraction of nanofluids on streamlines at $\mathrm{W} / \mathrm{H}=2.5$, (a) $\mathrm{Ra}=10^{4}$, (b) $\mathrm{Ra}=10^{5}$, (c) $\mathrm{Ra}=10^{6}$.

The temperature distributions for $\mathrm{W} / \mathrm{H}=2.5$ are presented by means of isotherms in figure (5). The isotherms do not change with changing the volume fractions of the nanofluids for all Rayleigh numbers. The isotherms are symmetrical about vertical center line for $\mathrm{Ra}=10^{4}$ and $\mathrm{Ra}=10^{5}$ for all volume fractions. As Rayleigh number increases, the thermal boundary layer adjacent to the cylinder becomes thinner and thinner.

At $\mathrm{Ra}=10^{4}$, the isotherms are similar for all volume fractions of the nanofluids. The mode of heat transfer is conduction and the effect of convection heat transfer is very low. The isotherms display as rings around the cylinder. As Rayleigh number increases to $\mathrm{Ra}=10^{5}$, the isotherms distorts below the cylinder due to the effect of the convection heat transfer. A thermal plume appears on the top of the cylinder. Two thermal plumes appear at the upper corners of the square cylinder. The isotherms appear as curved below the cylinder with low distortion due to the effect of the convection flow. At $\mathrm{Ra}=10^{6}$, the isotherms are nearly similar and independent of volume fractions of the nanofluids. The convection becomes the dominant mode of heat transfer. The width of the thermal plume at the middle of the cylinder becomes narrow, and it impinging on the top of the enclosure. The widths of the two thermal plums at the upper corners become narrow. The isotherms appear asymmetrical about the vertical center line. The thermal stratification (nearly horizontal and flat isotherms) is formed near the bottom region of the enclosure. 
International Journal of Recent advances in Mechanical Engineering (IJMECH) Vol.4, No.4, November 2015
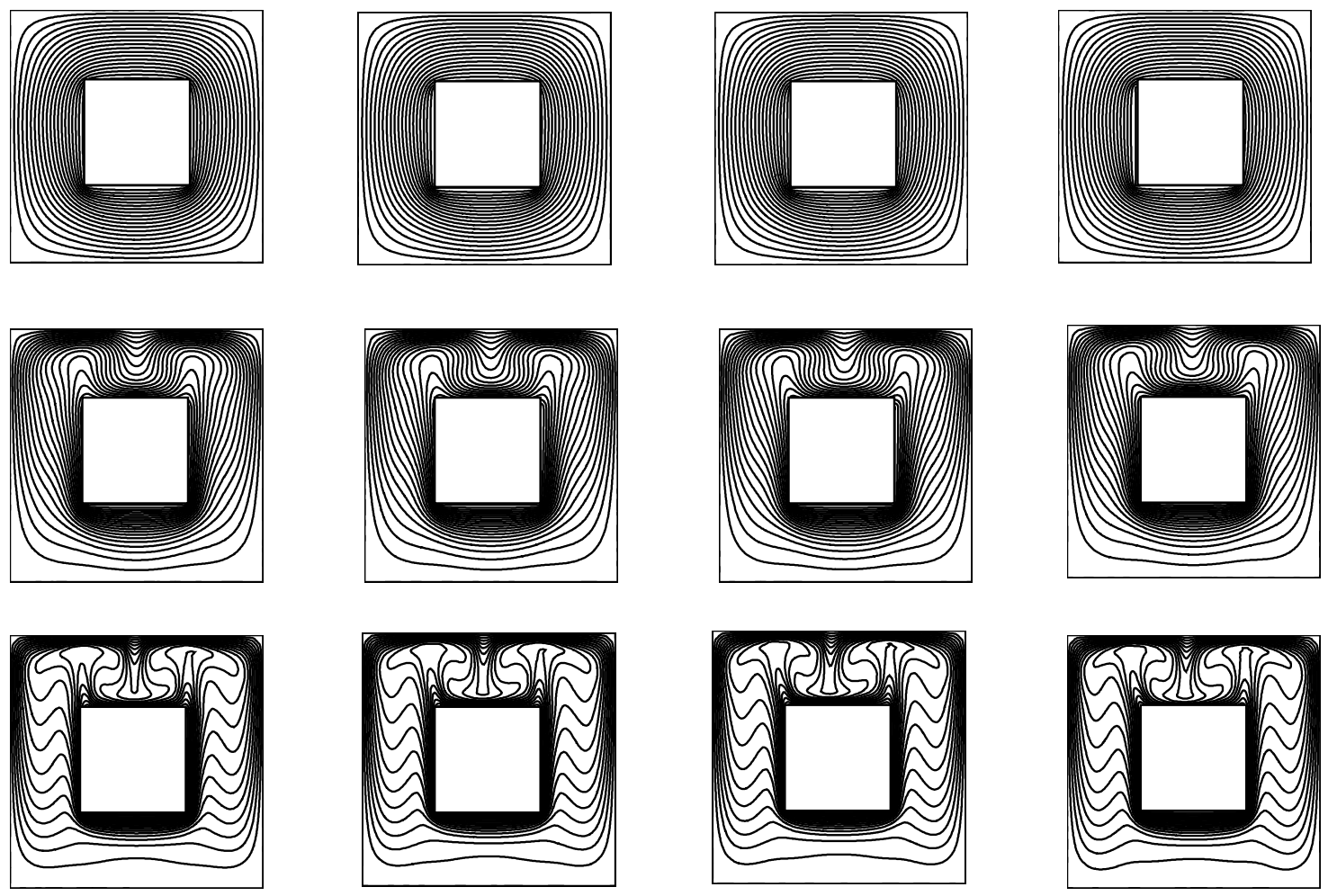

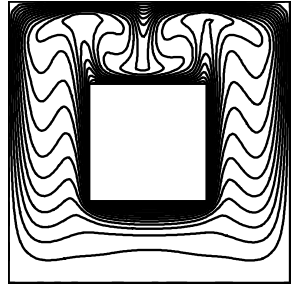

$\varphi=0.1$

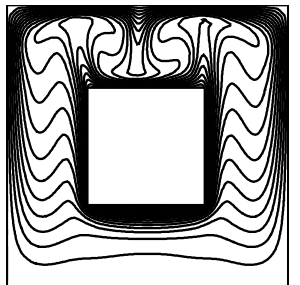

$\varphi=0.15$

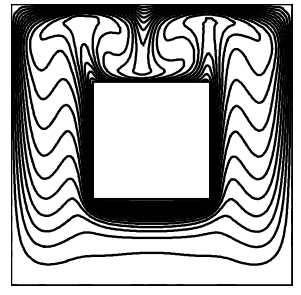

$\varphi=0.2$

Figure 5. Effect of volume fraction of nanofluids on isotherms at $\mathrm{W} / \mathrm{H}=2.5$ and (a) $\mathrm{Ra}=10^{4}$, (b) $\mathrm{Ra}=10^{5}$, (c) $\mathrm{Ra}=10^{6}$.

\subsection{Local and average Nusselt numbers}

The distributions of local Nusselt number around the square cylinder are presented in figures (6) for Rayleigh numbers $\mathrm{Ra}=10^{4}, 10^{5}$ and $10^{6}$ and $\varphi=0,0.05,0.1,0.15$ and 0.2. The measured angle starts from the middle of the right side of the enclosure and ends at the same point. The local Nusselt numbers increase with increasing volume fractions of the nanofluid for all Rayleigh numbers. The peak values of the local $\mathrm{Nu}$ occur at the corners of the square cylinder with all Rayleigh numbers and volume fractions of the nanofluid. The maximum enhancement of the local $\mathrm{Nu}$ occurs at the lower corners of the square cylinder. 
International Journal of Recent advances in Mechanical Engineering (IJMECH) Vol.4, No.4, November 2015
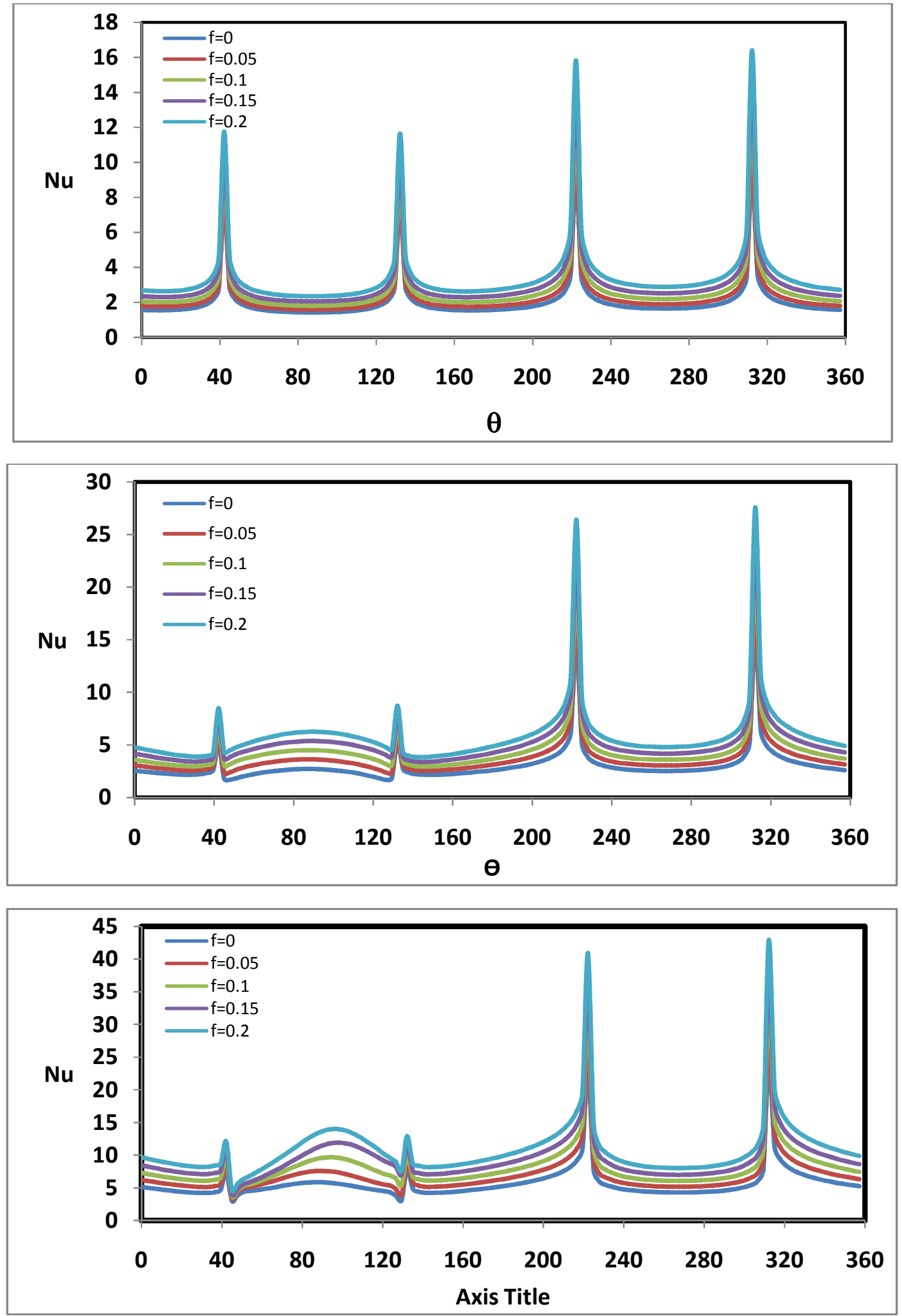

Figure 6. Effect of volume fraction of Nanofluids on the local Nusselt number for each enclosure width to square height W/D, (a) $\mathrm{Ra}=10^{4}$, (b) $\mathrm{Ra}=10^{5}$, (c) $\mathrm{Ra}=10^{6}$. 
The average Nusselt number is chosen as the measure to investigate the heat transfer from the square cylinder. The effect of volume fraction of the nanofluids on the average Nusselt numbers with $\mathrm{Ra}=10^{4}, 10^{5}$, and $10^{6}$ for enclosure width to the cylinder height $\mathrm{W} / \mathrm{H}=2.5$ is presented in figure (7). The volume fractions, $\varphi$ was varied as:0, $0.05,0.1,0.15,0.2$. The Nusselt number increases with increasing the Rayleigh number for all values of $\boldsymbol{\varphi}$. Nusselt number increases with increasing the volume fraction of the nanofluids. The enhancement of the Nusselt number due to increasing the nanofluid volume fraction is magnified with increasing Rayleigh number as indicated by the increased slop of the $\mathrm{Nu}-\varphi$ curves. The maximum enhancement in the Nusselt number when the volume fraction of nanoparticles is increased from 0 to 0.2 , using $R a=10^{4}$, is approximately $41 \%$, the maximum enhancement is around $49 \%$ for $\mathrm{Ra}=10^{5}$, whereas the maximum enhancement is around $48 \%$ for $\mathrm{Ra}=10^{6}$. This tells that the enhancement in heat transfer, due to the presence of nanoparticles, is pronounced for all Rayleigh numbers. The heat transfer enhances with increasing the volume fraction of the nanofluids because more particles suspended and the effect of thermal conductivity and viscosity of the nanofluids on the heat transfer.

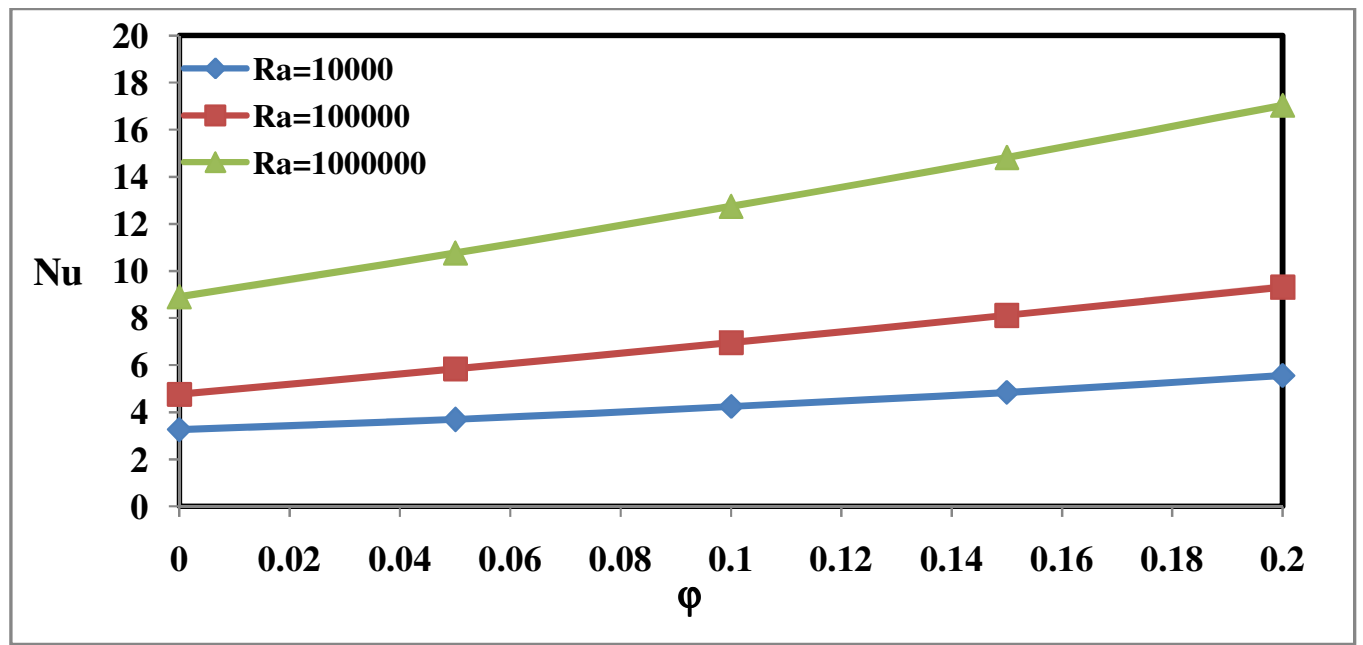

Figure 7. Effect of volume fraction of Nanofluids on the average Nusselt number for each enclosure width to square height W/D, (a) $\mathrm{Ra}=10^{4}$, (b) $\mathrm{Ra}=10^{5}$, (c) $\mathrm{Ra}=10^{6}$.

\subsection{Fluid flow and Heat Transfer Correlations}

The average Nusselt number and the maximum stream function from square cylinder in a vented enclosure are correlated in terms of the Rayleigh number in the range $\left(10^{4}-10^{6}\right)$ and the nanofluid volume fractions between $0-0.2$, using the results from the present work. The correlation of the average Nusselt number can be expressed as:

$\overline{\mathrm{Nu}}=1.491\left(0.194+\phi^{1.081}\right)$

With $\mathrm{R}^{2}=0.998$

The correlation of the maximum stream function can be expressed as:

$\psi_{\max }=0.035\left(0.209+\phi^{0.985}\right) \mathrm{Ra}^{0.58}$

With $\mathrm{R}^{2}=0.997$ 


\section{CONCLUSIONS}

Effect of the presence of the nanofluids on the natural convection heat transfer from square horizontal cylinder in a square enclosure was investigated numerically over a fairly wide range of $\mathrm{Ra}$. The main conclusions of the present work can be summarized as follows:

1. The numerical results show that the Nusselt number increases with increasing the Rayleigh number for all cases.

2. The flow patterns and isotherms display the effect of Ra, and volume fractions of the nanofluids on the thermal and hydrodynamic characteristics.

3. The Conduction is the dominant of the heat transfer at $\mathrm{Ra}=10^{4}$ for all cases. The contribution of the convective heat transfer increases with increasing the Rayleigh number.

4. The results show that the isotherms are nearly similar when the volume fraction of nanoparticles is increased from 0 to 0.2 for each Rayleigh number.

5. The streamlines are asymmetrical when the volume fraction of nanoparticles is increased from 0 to 0.2 for each Rayleigh number.

6. The average Nusselt number enhances gradually when the volume fraction of nanoparticles is increased from 0 to 0.2 for each Rayleigh number.

7. The correlation equation of the average Nusselt number is:

$$
\overline{\mathrm{Nu}}=1.491\left(0.194+\phi^{1.081}\right)
$$

8. The correlation equation of the maximum stream function is:

$\psi_{\max }=0.035\left(0.209+\phi^{0.985}\right) \mathrm{Ra}^{0.58}$

\section{REFERENCES}

[1] Ali O. M. (2008), "Experimental and Numerical Investigation of Natural Convection Heat Transfer From Cylinders of Different Cross Section Cylinder In a Vented Enclosure,” Ph. D., Thesis, College of Engineering, University of Mosul.

[2] S.U.S. Choi, (1995), "Enhancing thermal conductivity of fluids with nanoparticles, in: D.A. Signer, H.P. Wang (Eds.)," Developments and Applications of Non-Newtonian Flows, ASME, New York, 231(66), pp.99-105.

[3] Zi-Tao Yu, Xu Xu, Ya-Cai Hu, Li-Wu Fan, \& Ke-Fa Cen, (2011), " Numerical study of transient buoyancy-driven convective heat transfer of water-based nanofluids in a bottom-heated isosceles triang ular enclosure", International Journal of Heat and Mass Transfer, Vol. 54, pp. 526-532.

[4] Zi-Tao Yu, Xu Xu, Ya-Cai Hu, Li-Wu Fan, \& Ke-Fa Cen, (2012), "A numerical investigation of transient natural convection heat transfer of aqueous nanofluids in a horizontal concentric annulus," International Journal of Heat and Mass Transfer, Vol. 55, pp. 1141-1148.

[5] E. Abu-Nada, (2009), "Effects of variable viscosity and thermal conductivity of Al2O3-water nanofluid on heat transfer enhancement in natural convection," Int. J.Heat Fluid Flow, Vol. 30, 679690.

[6] Hakan F. Oztop, \& Eiyad Abu-Nada, (2008), "Numerical study of natural convection in partially heated rectangular enclosures filled with nanofluids," International Journal of Heat and Fluid Flow 29, 1326-1336.

[7] John D. Anderson Jr., (1995), "Computational Fluid Dynamics, the Basics with Applications," McGraw-Hill Book Company.

[8] Petrović Z., \& Stupar S., (1996), "Computational Fluid Dynamics, One," University of Belgrade.

[9] Brinkman, H.C., (1952), "The viscosity of concentrated suspensions and solutions," J. Chem. Phys. Vol. 20, pp. 571-581.

[10] Thomas P. D., \& Middlecoff J. F., (1980), "Direct Control of the Grid Point Distribution in Meshes Generated by Elliptic Equations," AIAA Journal, Vol. 18, pp. 652-656.

[11] Hoffmann K. A., (1989), "Computational Fluid Dynamics for Engineers," Engineering Education System, USA. 
International Journal of Recent advances in Mechanical Engineering (IJMECH) Vol.4, No.4, November 2015

[12] Thompson J. F., Warsi Z. U. A. and Mastin C. W., (1985), "Numerical Grid Generation: Foundations and Applications," Mississippi State, Mississippi.

[13] Ferziger J. H. and Peric M., (2002), "Computational Methods for Fluid Dynamics," Springer, New York.

[14] Roache, P., J., (1982), "Computational Fluid Dynamics," Hermosa publishers.

[15] Fletcher C., (1988), "Computational Techniques for Fluid Dynamics 2," Springer, Verlag.

[16] Moukalled F., Acharya S., (1996), "Natural convection in the annulus between concentric horizontal circular and square cylinders," Journal of Thermo-physics and Heat Transfer, Vol. 10, No. 3, pp. 524 -531 .

[17] Shu; and Zhu, (2002), "Efficient computation of natural convection in a concentric annulus between an outer square cylinder and an inner circular cylinder," International Journal for Numerical Methods in Fluids, Vol. 38, pp. 429-445. 